\section{BASIC statistics for IBM computers: An integrated instructional statistical package}

\author{
JOHN P. GALLA \\ Widener University, Chester, Pennsylvania
}

Since the introduction of the IBM PC in 1981, 14 papers on integrated statistical packages have appeared in the present publication (see Sidowski \& Campbell, 1987, pp. 539-540). Surprisingly, given the popularity of the IBM PC, only one (Anderson, 1984) was written specifically for that machine. ${ }^{1}$ The present article describes an integrated statistical package written specifically for the IBM family of computers, including the PC, XT, AT, and all PS/2 machines.

The package is designed primarily for instructional use and is completely menu driven. Decisions on how to proceed are made by choosing options from the current menu. From the Main Menu one can choose Data File Management, Descriptive Statistics, Inferential Statistics, Post Hoc Tests, or Correlation and Regression.

Data File Management allows one to create a random access data file. Data can be added to the file at any time. In addition, the file can be looked at, edited, sorted, and/or printed.

Descriptive Statistics includes mean and standard deviation, median, centiles, deciles, quartiles, frequency distributions (including cumulative frequency, relative frequency, and percentile ranks), and crosstabulations. The crosstabs program includes an optional chi-square contingency test.

Inferential statistics includes chi-square (one and two way), $t$ tests (one sample, two independent samples, and two related samples), simple $F$ test, and analysis of variance. Analysis of variance includes single-factor designs (randomized groups and randomized blocks), two-factor designs (two-factor ANOVA with one entry per cell, with equal or unequal $n s$, and with repeated measures on either one or both factors), a nested design (two-factor ANOVA with one nested factor), three-factor designs (three-factor ANOVA with equal or unequal $n s$ ), and a simple analysis of covariance.

Post Hoc Tests include Scheffé's, Tukey's, and Dunnett's tests. Correlation and Regression includes simple and multiple linear regression, Pearson $r$, and Kendall's tau. Four of the programs included in the package have been published separately by the author (Galla, 1981, 1982, 1984, 1987).

Language, computers, disk formats. The package is called BASIC Statistics because it is written in BASICA, a version of interpreted BASIC that comes with PC-DOS. Minimum system requirements are an IBM PC with $64 \mathrm{~K}$

Correspondence may be addressed to John P. Galla, Department of Psychology, Widener University, Chester, PA 19013. of RAM, one DSDD disk drive, and PC-DOS 2.0 or higher. However, it can run on an XT, AT, or any PS/2 machine and can be used with 5.25-in. floppies, 3.5-in. diskettes, or a hard disk.

Output. All computations are made with singleprecision (six-digit) accuracy. Many answers are printed in this fashion without modification. In some cases, however, for the purpose of formatting output, answers are rounded back to two or three decimal places. Rounding is achieved through the use of PRINT USING statements or BASICA's FIX function. Both rounding procdures preserve computational precision (Schneider, 1985).

Availability. The BASIC Statistics package has been field tested for the past 2 years in the Social Science Computer Laboratory at Widener University. All known bugs have been eliminated. A simple user's guide explains how to install and use the package on a floppy- or hard-diskbased system. A hard copy of the guide is provided with the 5.25-in. disk. A READ.ME file containing the guide is included on the 3.5-in. diskette.

The disk and user's guide may be obtained by writing to the author. Please include a blank disk and reusable disk mailer, or a $\$ 5$ check (to cover the disk and mailing costs). Make the check payable to Social Science Division, Widener University. Please do not send cash. Users with suggestions or questions about the package may call the author at (215) 499-4365.

\section{REFERENCES}

ANDERSON, D. E. (1984). PSYCHO-STATS PC: A statistical package for the IBM PC. Behavior Research Methods, Instruments, \& Computers, 16, 482.

ButLer, D. L., \& NeUdecker, W. (1989). A comparison of inexpensive statistical packages for microcomputers running MS-DOS. Behavior Research Methods, Instruments, \& Computers, 21, 113-120.

GALLA, J. P. (1981). Factorial analysis of variance with unequal observations: A BASIC program for microcomputers. Behavior Research Methods \& Instrumentation, 13, 699-700.

GALLA, J. P. (1982). Two-factor analysis of variance with one nested factor: A BASIC program for microcomputers. Behavior Research Methods \& Instrumentation, 14, 499.

Galla, J. P. (1984). Simple analysis of covariance: A BASIC program for microcomputers. Behavior Research Methods, Instruments, \& Computers, 16, 564-565.

GALLA, J. P. (1987). Kendall's tau and Kendall's partial correlation: Two BASIC programs for microcomputers. Behavior Research Methods, Instruments, \& Computers, 19, 55-56.

SCHNEIDER, D. I. (1985). Handbook of BASIC for the IBM PC. Bowie, MD: Brady Communications.

Sidowski, J. B., \& CAMPBELl, G. E. (EDS.) (1987). Computer technology: Index to articles in Behavior Research Methods, Instruments, \& Computers from 1977 to 1987. Behavior Research Methods, Instruments, \& Computers, 19, 487-560.

\section{NOTE}

1. For a comparison of inexpensive statistical packages for MS and PC-DOS computers, see Butler and Neudecker (1989).

(Manuscript received February 24, 1989; revision accepted for publication May 24, 1989.) 